\title{
Clinical characteristics of different subtypes and risk factors for the severity of illness in patients with COVID-19 in Zhejiang, China
}

Shan-Yan Zhang, Jiang-Shan Lian, Jian-Hua Hu, Xiao-Li Zhang, Ying-Feng Lu, Huan Cai, Jue-Qing Gu, Chan-Yuan Ye, Ci-Liang Jin, Guo-Dong Yu, Hong-Yu Jia, Yi-Min Zhang, Ji-Fang Sheng, Lan-Juan Li and Yi-Da Yang*

\begin{abstract}
Background: The outbreak of coronavirus disease 2019 (COVID-19) is now becoming an enormous threat to public health. The clinical spectrum of COVID-19 is extensive, of which critical cases are with rapid disease progression and high mortality. The aim of our study is to summarize the characteristics of different subtypes and explore risk factors of illness severity for early identification and prompt treatment.

Methods: In this retrospective study, we collected data of patients confirmed COVID-19 in Zhejiang Province from 17 January to 12 February 2020. According to the definition of clinical classification, we divided confirmed cases into four types, and summarize epidemiological and clinical characteristics, laboratory and radiograph findings, treatments, and outcomes, respectively. Moreover, we used univariate and multivariate ordinal logistic regression models to explore risk factors for the severity of illness in patients with COVID-19.

Results: A total of 788 patients were enrolled in our study, of whom 52 cases (6.6\%) were mild type, 658 cases (83.5\%) were common type, 61 cases (7.2\%) were severe type, and 17 cases (2.2\%) were critical type. Multivariate ordinal logistic regression demonstrated increasing odds of the severity of illness in patients with COVID-19 associated with male (odds ratio $[O R]=1.7,95 \%$ confidence interval $[C l]: 1.2-2.6 P=0.008)$, fever $(O R=3.6,95 \% \mathrm{Cl}$ : 2.1-6.3, $P<0.001)$, cough $(O R=1.7,95 \% C l: 1.0-2.9, P=0.041)$, hemoptysis $(O R=3.4,95 \% C l: 1.1-10.3, P=0.032)$, gastrointestinal symptoms $(O R=1.9,95 \% C l: 1.0-3.5, P=0.047)$, hypertension $(O R=2.6,95 \% C l: 1.2-5.6, P=0.013)$. With the increase of age-grading, risk for the severity of illness was gradually higher $(\leq 18$ years [OR=1.0], 19-40 years $[O R=12.7,95 \% \mathrm{Cl}: 4.5-36.0, P<0.001], 41-65$ years $[O R=14.8,95 \% \mathrm{Cl}: 5.2-42.1, P<0.001]$, $\geq 66$ years $[O R=$ 56.5, 95\% Cl: 17.1-186.5, $P<0.001])$.

Conclusions: Clinicians should pay close attention to these features in patients with COVID-19 including older age, male, fever, cough, hemoptysis, gastrointestinal symptoms and hypertension to identify the severity of illness as early as possible.
\end{abstract}

Keywords: COVID-19, SARS-CoV-2, Subtype, Risk factor, Gastrointestinal symptom

\footnotetext{
* Correspondence: yidayang65@zju.edu.cn

State Key Laboratory for Diagnosis and Treatment of Infectious Diseases, National Clinical Research Center for Infectious Diseases, Collaborative Innovation Center for Diagnosis and Treatment of Infectious Diseases, The First Affiliated Hospital, College of Medicine, Zhejiang University, Hangzhou, China
}

C C The Author(s). 2020 Open Access This article is licensed under a Creative Commons Attribution 4.0 International License, which permits use, sharing, adaptation, distribution and reproduction in any medium or format, as long as you give appropriate credit to the original author(s) and the source, provide a link to the Creative Commons licence, and indicate if changes were made. The images or other third party material in this article are included in the article's Creative Commons licence, unless indicated otherwise in a credit line to the material. If material is not included in the article's Creative Commons licence and your intended use is not permitted by statutory regulation or exceeds the permitted use, you will need to obtain permission directly from the copyright holder. To view a copy of this licence, visit http://creativecommons.org/licenses/by/4.0/ The Creative Commons Public Domain Dedication waiver (http://creativecommons.org/publicdomain/zero/1.0/) applies to the data made available in this article, unless otherwise stated in a credit line to the data. 


\section{Background}

In December, 2019, a cluster of patients with pneumonia of unknown cause appeared in Wuhan, Hubei Province, China. By 7 January 2020, China rapidly isolated the novel coronavirus and shared the viral genome sequence to World Health Organization (WHO) [1]. The novel coronavirus was identified as a novel enveloped RNA betacoronavirus and named 2019 novel coronavirus (later named as severe acute respiratory syndrome coronavirus 2 [SARS-CoV-2] by the International Committee on Taxonomy of Viruses), which has a phylogenetic similarity to severe acute respiratory syndrome coronavirus (SARS-CoV), but the contagosity is higher than SARS-CoV and Middle East respiratory syndrome coronavirus (MERS-CoV) [2]. In order to prevent the epidemic of this contagion, Chinese government made a decision to temporarily shut down the traffic departing from Wuhan on 23 January 2020 and adopted a series of control measures.

WHO declared the spread of SARS-CoV-2 was listed as a public health emergency of international concern, and subsequently designated the pneumonia infected by SARS-CoV-2 as coronavirus disease 2019 (COVID-19) [3]. Until 19 April 2020, COVID-19 has swept across 213 countries and regions which reported 2245872 confirmed cases and 152707 deaths. The largest number of confirmed cases were in the United States, followed by Spain and Italy [4]. This phenomenon signified fighting with COVID-19 is not only a matter for China, but an imperative event for global.

Nowadays, the majority of studies on COVID-19 in China are focused on Wuhan, the hardest-hit area, and little is known about the clinical features of COVID-19 outside of Wuhan [5-7]. The study of Chang et al. [8] included 13 cases in Beijing and the research of Xu et al. [9] enrolled 62 cases in Zhejiang, however, due to the small sample size, clinical characteristics might be not comprehensive. Researches with a larger number of confirmed cases were urgently needed outside of Wuhan. The clinical spectrum of COVID-19 appears to be wide, comprising mild type without pneumonia, common type with pneumonia, severe type with respiratory distress, and critical type with respiratory failure, shock or even death [10]. Diverse subtypes have their unique features, whether in epidemiology or laboratory results. A study with 72314 cases reported by the Chinese Center for Disease Control and Prevention (China CDC) showed that the case-fatality rate was $49.0 \%$ among critical cases [11]. Therefore, mastering the characteristics of different subtypes and early identification of the severity of illness is of great significance for the treatment.

Hence, the aim of our study is to summarize the epidemiologic and clinical characteristics, laboratory and radiograph findings, treatments, and outcomes of different subtypes of patients with COVID-19 in Zhejiang Province. On this basis, we want to explore risk factors for the severity of illness in patients with COVID-19 and appeal to clinicians to attach importance to these factors.

\section{Methods}

\section{Data sources and ethics}

We conducted a retrospective study investigating on the epidemiological, clinical, laboratory, radiograph, treatments and outcomes characteristics of confirmed cases of COVID-19 in Zhejiang Province from 17 January to 12 February 2020. Diagnosis of COVID-19 was in accordance with the interim guidance from the WHO [12]. A confirmed case of COVID-19 was defined as a positive result on real-time reverse transcriptase polymerase chain reaction (RT-PCR) assay of sputum and throat swab specimens. Only laboratory-confirmed patients were enrolled in our study. Data were uniformly collected by the Health Commission of Zhejiang Province, where all patients were allocated at specific hospitals for unified treatment according to the government emergency rule. All data enrolled in our study had been shared with WHO and the preliminary results were reported to the authority of Zhejiang Province.

Information of medical records were gathered and sent to the data collection center in Hangzhou. Demographic, epidemiological, clinical, laboratory, treatments and outcomes data were exacted from electronic medical records using a standardized data collection form. A group of doctors who have experiences in treating the patients with COVID-19 reviewed and disposed the data. When information was incomplete, the working team in Hangzhou would contact the doctor in charge for explanation.

This study was approved by the Clinical Research Ethics Committee of the First Affiliated Hospital, College of Medicine, Zhejiang University (No. IIT20200005C). Written informed consent was waived by the ethics commission of the designated hospital, and oral consent was obtained from patients.

\section{Procedures}

Sputum and throat swab specimens collected from all patients were tested by RT-PCR for SARS-CoV-2 RNA. Briefly, the CDC of Zhejiang Province and at municipal level, and the First Affiliated Hospital, School of Medicine, Zhejiang University were responsible for confirmation of SARS-CoV-2, with national authorization.

Laboratory tests were conducted on admission, including blood routine examinations, serum biochemical tests, coagulation function examinations, infection-related biomarkers, and an identification of other respiratory pathogens such as influenza A virus, influenza B virus, 
parainfluenza virus, adenovirus and respiratory syncytial virus. Chest radiograph or computed tomography (CT) was done for all inpatients at admission. Treatment measures and outcomes were followed up to 12 February 2020.

\section{Case definitions}

The illness severity of COVID-19 was defined according to the Chinese management guideline for COVID-19 (version 6.0) [13]. Patients with COVID-19 was categorized as mild, common, severe, and critical according to the illness severity. Mild type was defined as mild symptoms and no pneumonia on imaging. Common type was defined as having respiratory tract symptoms and imaging with pneumonia. Severe type was defined as satisfying any of the following items: 1) respiratory distress and respiratory frequency $\geq 30 / \mathrm{min} ; 2$ ) blood oxygen saturation $\leq 93 \%$ at rest; 3$) \mathrm{PaO}_{2} / \mathrm{FiO}_{2}$ ratio $\leq 300 \mathrm{mmHg}$; 4 ) Lung infiltrates $>50 \%$ within $24-48 \mathrm{~h}$. Critical type was defined as satisfying any of the following items: 1) respiratory failure occurs and require mechanical ventilation; 2) shock occurs; 3) combined with other organ failure and requires ICU monitoring and treatment. The incubation period was defined as the time from exposure to the onset of illness, which was estimated among patients who could provide the exact data of close contact with confirmed or suspected individuals. Family cluster was defined as occurring two or more cases with fever and/or respiratory symptoms within the family in recent 2 weeks. Fever was defined as axillary temperature of at least $37.3^{\circ} \mathrm{C}$. Gastrointestinal symptoms included nausea, emesis and diarrhea.

\section{Discharge criteria}

Once the temperature returned to normal for more than 3 days, respiratory symptoms significantly improved, the imaging of lung obviously absorbed, and two consecutive negative results for SARS-CoV-2 antigen (sampling interval at least 1 day), patients could be discharged from hospital.

\section{Statistical analysis}

Continuous variables were presented as median (interquartile range [IQR]) and compared using KruskalWallis. Categorical variables were presented as frequency (percentages), and compared using the $\chi^{2}$ test or Fisher's exact test when appropriate.

To analyze risk factors for the severity of illness in patients with COVID-19, univariate and multivariate ordinal logistic regression models were used. Variables with $P<0.05$ in the univariate models were selected into the multivariate model for calculating. A two-sided $\alpha$ of $<0.05$ was considered statistically significant. All the analyses were done with SPSS version 25.0 (IBM Corporation, Armonk, NY, USA).

The Kaplan-Meier method was used to estimate hospitalization time, and the log rank test was applied for comparisons among mild, common, and severe type. The Kaplan-Meier analysis was performed using 'survival' packages in $\mathrm{R}$ version 3.6.1 (R Foundation, Vienna, Austria).

\section{Results}

Demographic, epidemiologic, and clinical characteristics From 17 January 2020 to 12 February 2020, clinical data were collected on 788 patients with COVID-19 in Zhejiang Province. According to the definition of clinical classification, they were divided into 52 cases $(6.6 \%)$ of mild type, 658 cases (83.5\%) of common type, 61 cases (7.7\%) of severe type, and 17 cases (2.2\%) of critical type.

As shown in Table 1, the median age in mild, common, severe, and critical type was 37.5 years (IQR: $19.3-$ 45.8 ), 45.0 years (IQR: $35.0-55.0$ ), 55.0 years (IQR: 44.0 62.0), and 70.0 years (IQR: $55.0-73.0$ ). The proportion of male patients was account for 50.0, 50.0, 63.9 and 76.5\%, respectively. Hypertension was the most common underlying disease and there were significant differences among the four subtypes $(9.6 \%$ vs $13.2 \%$ vs $31.1 \%$ vs $88.2 \%, P<0.001)$. In both severe and critical type, the ratio of patients with gastrointestinal symptoms exceeded $15 \%$.

\section{Laboratory and radiograph findings}

On admission, the majority of leucocyte in all subtypes were normal or decreased. As shown in Table 2, the four types had significant differences in neutrophil count, lymphocyte count, platelets count, albumin (ALB), aspartate aminotransferase (AST), sodium, blood urea nitrogen $(\mathrm{BUN})$, creatinine $(\mathrm{CR})$, creatinine kinase $(\mathrm{CK})$, lactate dehydrogenase (LDH), C-reactive protein (CRP) and procalcitonin $(\mathrm{PCT})(P<0.05)$. In contrast, there were no significant differences in hemoglobin, International normalized ration (INR), alanine aminotransferase (ALT), total bilirubin (TB) and potassium $(P>0.05)$.

Multiple mottling and ground-glass opacity were typical imaging manifestations of patients with COVID-19. The proportion of it in common, severe, and critical type were $27.8,60.7$, and $88.2 \%$, respectively.

\section{Treatments and outcomes}

Patients with COVID-19 were quarantined in designated hospital and a total of 668 patients received antiviral treatments in our research. As shown in Table 3, interferon- $\alpha$ inhalation, lopinavir/ritonavir and arbidol were the most commonplace antiviral regimen in all subtypes. Glucocorticoids were not used in mild type, but in all critical types, and there were significant 
Table 1 Demographic, epidemiologic and clinical characteristics of different subtypes in patients with COVID-19

\begin{tabular}{|c|c|c|c|c|c|}
\hline Characteristic & $\begin{array}{l}\text { Mild type } \\
(n=52)\end{array}$ & $\begin{array}{l}\text { Common type } \\
(n=658)\end{array}$ & $\begin{array}{l}\text { Severe type } \\
(n=61)\end{array}$ & $\begin{array}{l}\text { Critical type } \\
(n=17)\end{array}$ & $P$ value \\
\hline Age (years) & $37.5(19.3-45.8)$ & $45.0(35.0-55.0)$ & $55.0(44.0-62.0)$ & $70.0(55.0-73.0)$ & $<0.001$ \\
\hline Distribution & & & & & $<0.001$ \\
\hline$\leq 18$ & $12(23.1)$ & $9(1.4)$ & $0(0.0)$ & $0(0.0)$ & \\
\hline $19-40$ & $16(30.8)$ & $241(36.6)$ & $11(18.0)$ & $0(0.0)$ & \\
\hline $41-65$ & $24(46.2)$ & $350(53.2)$ & 39 (63.9) & $7(41.2)$ & \\
\hline$\geq 66$ & $0(0.0)$ & $58(8.8)$ & $11(18.0)$ & $10(58.8)$ & \\
\hline Sex (male) & $26(50.0)$ & $329(50.0)$ & $39(63.9)$ & $13(76.5)$ & 0.034 \\
\hline BMI $\left(\mathrm{kg} / \mathrm{m}^{2}\right)$ & & & & & $<0.001$ \\
\hline$<18.5$ & $5 / 25(20.0)$ & 20/370 (5.4) & $0 / 36(0.0)$ & $0 / 13(0.0)$ & \\
\hline $18.5-<25$ & $17 / 25(68.0)$ & $240 / 370(64.9)$ & $17 / 36(47.2)$ & $7 / 13(53.8)$ & \\
\hline$\geq 25$ & $3 / 25(12.0)$ & $110 / 370(29.7)$ & 19/36 (52.8) & $6 / 13(46.2)$ & \\
\hline Current smoker & $2(3.8)$ & $45(6.8)$ & $5(8.2)$ & $2(11.8)$ & 0.544 \\
\hline Exposure history in Wuhan & $23(44.2)$ & $331(50.3)$ & $31(50.8)$ & $8(47.1)$ & 0.853 \\
\hline Incubation period (days) & $7.0(3.0-11.5)(n=17)$ & $6.0(3.0-9.0)(n=156)$ & $3.0(2.0-5.5)(n=14)$ & $7.0(n=1)$ & 0.239 \\
\hline Family cluster & $25(48.1)$ & $152(23.1)$ & $11(18.0)$ & $7(41.2)$ & $<0.001$ \\
\hline $\begin{array}{l}\text { Time from illness onset to first } \\
\text { hospital admission (days) }\end{array}$ & $2.5(1.0-4.0)$ & $3.0(1.0-6.0)$ & $5.0(2.0-8.0)$ & $5.0(2.5-6.5)$ & $<0.001$ \\
\hline \multicolumn{6}{|l|}{ Coexisting disorder } \\
\hline Any & $10(19.2)$ & $161(24.5)$ & $31(50.8)$ & $16(94.1)$ & $<0.001$ \\
\hline Hypertension & $5(9.6)$ & $87(13.2)$ & $19(31.1)$ & $15(88.2)$ & $<0.001$ \\
\hline Heart disease & $0(0.0)$ & $9(1.4)$ & $1(1.6)$ & $1(5.9)$ & 0.254 \\
\hline Diabetes & $3(5.8)$ & $42(6.4)$ & $8(13.1)$ & $4(23.5)$ & 0.019 \\
\hline Chronic obstructive pulmonary disease & $0(0.0)$ & $0(0.0)$ & $2(3.3)$ & $1(5.9)$ & 0.001 \\
\hline Cancer & $0(0.0)$ & $3(0.5)$ & $3(4.9)$ & $0(0.0)$ & 0.030 \\
\hline Chronic liver disease & $1(1.9)$ & $26(4.0)$ & $2(3.3)$ & $2(11.8)$ & 0.351 \\
\hline Chronic renal disease & $0(0.0)$ & $5(0.8)$ & $1(1.6)$ & $1(5.9)$ & 0.150 \\
\hline \multicolumn{6}{|l|}{ Symptoms on admission } \\
\hline Fever & $28(53.8)$ & $534(81.2)$ & $57(93.4)$ & $17(100.0)$ & $<0.001$ \\
\hline Cough & $19(36.5)$ & $426(64.7)$ & $49(80.3)$ & $12(70.6)$ & $<0.001$ \\
\hline Sputum production & $8(15.4)$ & $219(33.3)$ & $29(47.5)$ & $9(52.9)$ & 0.001 \\
\hline Hemoptysis & $0(0.0)$ & $8(1.2)$ & $6(9.8)$ & $1(5.9)$ & 0.001 \\
\hline Sore throat & $8(15.4)$ & $95(14.4)$ & $7(11.5)$ & $1(5.9)$ & 0.796 \\
\hline Nasal obstruction & $6(11.5)$ & $41(6.2)$ & $0(0.0)$ & $0(0.0)$ & 0.034 \\
\hline Myalgia & $4(7.7)$ & $68(10.3)$ & $14(23.0)$ & $5(29.4)$ & 0.004 \\
\hline Fatigue & $10(19.2)$ & $105(16.0)$ & $18(29.5)$ & $6(35.3)$ & 0.013 \\
\hline Gastrointestinal symptom & $7(13.5)$ & $63(9.6)$ & $12(19.7)$ & $6(35.3)$ & 0.002 \\
\hline Headache & $2(3.8)$ & $61(9.3)$ & $11(18.0)$ & $1(5.9)$ & 0.076 \\
\hline
\end{tabular}

Data are presented as medians (interquartile ranges, IQR), $n(\%)$ and $n / N(\%)$

differences in the use among the four types $(0.0 \%$ vs $8.2 \%$ vs $47.5 \%$ vs $100.0 \%, P<0.001)$. Similar to glucocorticoids, there were significant differences among the four types based on the use intravenous immunoglobulin $(0.0 \%$ vs $3.6 \%$ vs $42.6 \%$ vs $70.6 \%, P<0.001)$. Till 12 February 2020, none of patients used extracorporeal membrane oxygenation (ECMO) and continuous renalreplacement therapy (CRRT).

At the endpoint of our study, 21 cases $(40.4 \%)$ of mild type, 273 cases $(41.5 \%)$ of common type, 27 cases (44.3\%) of severe type, and 1 case $(5.9 \%)$ of critical type discharged from hospital, and none of the patients died. 
Table 2 Laboratory and radiograph findings of different subtypes in patients with COVID-19 on admission

\begin{tabular}{|c|c|c|c|c|c|}
\hline Variable & $\begin{array}{l}\text { Mild type } \\
(n=52)\end{array}$ & $\begin{array}{l}\text { Common type } \\
(n=658)\end{array}$ & $\begin{array}{l}\text { Severe type } \\
(n=61)\end{array}$ & $\begin{array}{l}\text { Critical type } \\
(n=17)\end{array}$ & $P$ value \\
\hline \multicolumn{6}{|l|}{ Blood routine } \\
\hline Leucocyte count $\left(\times 10^{9} / \mathrm{L}\right)$ & $5.7(4.3-7.1)$ & $4.7(3.8-5.8)$ & $4.9(3.8-6.6)$ & $6.8(3.8-8.8)$ & 0.002 \\
\hline$<4$ & $9(17.3)$ & $201(30.5)$ & $19(31.1)$ & $5(29.4)$ & \\
\hline$>10$ & $1(1.9)$ & $10(1.5)$ & $4(6.6)$ & $3(17.6)$ & \\
\hline Neutrophil count $\left(\times 10^{9} / \mathrm{L}\right)$ & $3.6(2.0-5.0)$ & $2.9(2.2-3.8)$ & $3.2(2.6-5.0)$ & $5.8(2.8-8.0)$ & $<0.001$ \\
\hline$>7$ & $3(5.8)$ & $17(2.6)$ & $7(11.5)$ & $7(41.2)$ & \\
\hline Lymphocyte count $\left(\times 10^{9} / \mathrm{L}\right)$ & $1.3(1.1-1.9)$ & $1.2(0.9-1.6)$ & $0.9(0.6-1.2)$ & $0.5(0.4-0.8)$ & $<0.001$ \\
\hline$<0.8$ & $8(15.4)$ & $91(13.8)$ & $23(37.7)$ & $12(70.6)$ & \\
\hline Hemoglobin (g/L) & $139.0(131.0-152.0)$ & $138.0(127.0-150.0)$ & $139.0(122.5-153.0)$ & $128.0(117.0-153.5)$ & 0.332 \\
\hline Platelets count $\left(\times 10^{9} / \mathrm{L}\right)$ & $206.0(171.0-241.3)$ & $180.0(147.8-221.3)$ & $172.0(138.0-214.0)$ & $146.0(122.0-181.5)$ & 0.001 \\
\hline$<100$ & $0(0.0)$ & $23(3.5)$ & $2(3.3)$ & $2(11.8)$ & \\
\hline \multicolumn{6}{|l|}{ Coagulation function } \\
\hline International normalized ration (INR) & $1.0(1.0-1.1)$ & $1.0(1.0-1.1)$ & $1.0(1.0-1.1)$ & $1.0(1.0-1.2)$ & 0.070 \\
\hline \multicolumn{6}{|l|}{ Blood biochemistry } \\
\hline Albumin (ALB, g/L) & $42.5(40.5-45.7)$ & $41.7(38.7-43.9)$ & $38.7(35.8-41.6)$ & $35.9(30.8-37.6)$ & $<0.001$ \\
\hline Alanine aminotransferase (ALT, U/L) & $20.0(12.0-39.1)$ & $21.1(15.0-33.0)$ & $24.0(16.5-34.5)$ & $20.5(14.0-30.8)$ & 0.528 \\
\hline Aspartate aminotransferase (AST, U/L) & $22.0(16.5-34.0)$ & $25.0(19.1-32.2)$ & $28.0(22.0-40.0)$ & $30.5(25.0-41.8)$ & 0.002 \\
\hline$>40$ & $7(13.5)$ & $76(11.6)$ & $13(21.3)$ & $5(29.4)$ & \\
\hline Total bilirubin (TB) $(\mu \mathrm{mol} / / \mathrm{L})$ & $8.8(6.2-11.6)$ & $9.5(7.0-13.1)$ & $10.7(7.8-15.6)$ & $10.3(8.0-14.6)$ & 0.205 \\
\hline Potassium (mmol/L) & $3.8(3.6-4.2)$ & $3.8(3.6-4.1)$ & $3.9(3.6-4.2)$ & $3.7(3.2-3.9)$ & 0.112 \\
\hline Sodium (mmol/L) & $139.0(138.0-141.0)$ & $138.5(136.3-140.2)$ & $137.4(135.0-139.3)$ & $136.0(130.1-137.8)$ & $<0.001$ \\
\hline Blood urea nitrogen $(\mathrm{BUN}, \mathrm{mmol} / \mathrm{L})$ & $4.2(3.2-4.7)$ & $3.7(3.0-4.6)$ & $4.0(3.2-5.6)$ & $5.8(3.6-12.3)$ & 0.001 \\
\hline Creatinine $(C R, \mu \mathrm{mol} / L)$ & $66.0(58.0-76.0)$ & $65.3(55.0-78.0)$ & $71.0(62.5-80.5)$ & $79.0(65.9-106.5)$ & 0.002 \\
\hline Creatinine kinase $(C K, U / L)$ & $60.5(42.5-75.3)$ & $68.5(47.0-105.3)$ & $76.0(56.5-120.5)$ & $146.0(54.3-255.5)$ & $<0.001$ \\
\hline Lactate dehydrogenase (LDH, U/L) & $175.0(147.0-241.0)$ & $207.5(168.0-254.0)$ & $272.0(221.5-366.5)$ & $320.5(256.3-356.5)$ & $<0.001$ \\
\hline$>250$ & $11(21.2)$ & $167(25.4)$ & $39(63.9)$ & $13(76.5)$ & \\
\hline \multicolumn{6}{|l|}{ Infection-related biomarkers } \\
\hline C-reactive protein (CRP, mg/L) & $1.9(0.5-5.5)$ & $7.7(2.5-19.4)$ & $26.2(10.4-51.1)$ & $45.5(14.7-84.9)$ & $<0.001$ \\
\hline Procalcitonin (PCT, ng/ml) & $0.1(0.0-0.1)$ & $0.1(0.0-0.1)$ & $0.1(0.0-0.1)$ & $0.1(0.0-0.2)$ & 0.013 \\
\hline \multicolumn{6}{|l|}{ Chest $\mathrm{x}$-ray/CT finding } \\
\hline Multiple mottling and ground-glass opacity & $0(0.0)$ & 183(27.8) & $37(60.7)$ & $15(88.2)$ & $<0.001$ \\
\hline
\end{tabular}

Data are presented as medians (interquartile ranges, IQR), $n(\%)$ and $n / N(\%)$

Kaplan-Meier analysis showed a significant difference in hospitalization time among mild type, common type and severe type (Fig. 1).

\section{Risk factors for the severity of illness in patients with COVID-19}

As shown in Table 4, the variables with $P<0.05$ in the univariate ordinal logistic regression model were selected into the multivariate ordinal logistic regression model for the severity of illness in patients with COVID-19. There was no multicollinearity within the variables in the final model. Results of multivariate ordinal logistic regression showed the severity of illness was relevant to the age-grading, sex, fever, cough, hemoptysis, gastrointestinal symptoms and hypertension. Multivariate ordinal logistic regression demonstrated increasing odds of the severity of illness in patients with COVID-19 associated with male (odds ratio $[O R]=1.7,95 \%$ confidence interval $[C I]$ : $1.2-2.6, P=0.008)$, fever $(O R=3.6,95 \% C I$ : 2.1-6.3, $P<0.001)$, cough $(O R=1.7,95 \% C I: 1.0-2.9$, $P=0.041)$, hemoptysis $(O R=3.4,95 \% C I: 1.1-10.3, P=$ $0.032)$, gastrointestinal symptoms $(O R=1.9,95 \% C I$ : $1.0-3.5, P=0.047)$, hypertension $(O R=2.6,95 \% C I: 1.2-$ $5.6, P=0.013)$. With the increase of age-grading, the risk for the severity was gradually higher $(\leq 18$ years $[O R=$ $1.0], \quad 19-40$ years $\quad[O R=12.7, \quad 95 \% \quad C I: \quad 4.5-36.0$, 
Table 3 Treatments, and clinical outcomes of different subtypes in patients with COVID-19

\begin{tabular}{|c|c|c|c|c|c|}
\hline Variable & $\begin{array}{l}\text { Mild type } \\
(n=52)\end{array}$ & $\begin{array}{l}\text { Common type } \\
(n=658)\end{array}$ & $\begin{array}{l}\text { Severe type } \\
(n=61)\end{array}$ & $\begin{array}{l}\text { Critical type } \\
(n=17)\end{array}$ & $P$ value \\
\hline Shock & $0(0.0)$ & $0(0.0)$ & $0(0.0)$ & $2(11.8)$ & $<0.001$ \\
\hline Time from illness onset to antiviral treatments (days) & $3.0(1.0-4.5)$ & $4.0(2.0-7.0)$ & $7.0(4.0-9.0)$ & $5.0(2.0-6.8)$ & $<0.001$ \\
\hline Antiviral treatments & $41(78.8)$ & $552(83.9)$ & $59(98.7)$ & $16(94.1)$ & 0.010 \\
\hline Interferon-a inhalation + lopinavir/ritonavir & $9 / 41(22.0)$ & $139 / 552(25.2)$ & $16 / 59(27.1)$ & $1 / 16(6.3)$ & \\
\hline Interferon-a inhalation+ arbidol & $1 / 41(2.4)$ & $33 / 552(6.0)$ & $7 / 59(11.9)$ & $0 / 16(0.0)$ & \\
\hline Interferon-a inhalation + lopinavir/ritonavir+ arbidol & $14 / 41(34.1)$ & 191/552 (34.6) & $23 / 59(39.0)$ & $7 / 16(43.8)$ & \\
\hline Lopinavir/ritonavir + arbidol & $6 / 41(14.6)$ & $62 / 552(11.2)$ & $1 / 59(1.7)$ & $4 / 16(25.0)$ & \\
\hline Lopinavir/ritonavir & $5 / 41(12.2)$ & $60 / 552(10.9)$ & $3 / 59(5.1)$ & $0 / 16(0.0)$ & \\
\hline Arbidol & 2/41 (4.9) & $33 / 552(6.0)$ & $6 / 61(10.2)$ & $0 / 16(0.0)$ & \\
\hline Interferon-a inhalation only & $4 / 41(9.8)$ & $29 / 552(5.3)$ & $2 / 61(3.4)$ & $0 / 16(0.0)$ & \\
\hline others & $0 / 41(0.0)$ & $5 / 552(0.9)$ & $1 / 61(1.7)$ & $4 / 16(25.0)$ & \\
\hline Glucocorticoids & $0(0.0)$ & $54(8.2)$ & $29(47.5)$ & $17(100.0)$ & $<0.001$ \\
\hline Intravenous immunoglobulin & $0(0.0)$ & $24(3.6)$ & $26(42.6)$ & $12(70.6)$ & $<0.001$ \\
\hline Extracorporeal membrane oxygenation (ECMO) & $0(0.0)$ & $0(0.0)$ & $0(0.0)$ & $0(0.0)$ & \\
\hline Continuous renal-replacement therapy (CRRT) & $0(0.0)$ & $0(0.0)$ & $0(0.0)$ & $0(0.0)$ & \\
\hline \multicolumn{6}{|l|}{ Clinical outcomes at data cutoff } \\
\hline Discharge from hospital & $21(40.4)$ & 273 (41.5) & $27(44.3)$ & $1(5.9)$ & 0.029 \\
\hline Hospitalization & 31 (59.6) & $385(58.5)$ & $34(55.7)$ & $16(94.1)$ & 0.029 \\
\hline Death & $0(0.0)$ & $0(0.0)$ & $0(0.0)$ & $0(0.0)$ & \\
\hline
\end{tabular}

Data are presented as medians (interquartile ranges, IQR), $n(\%)$ and $n / N(\%)$

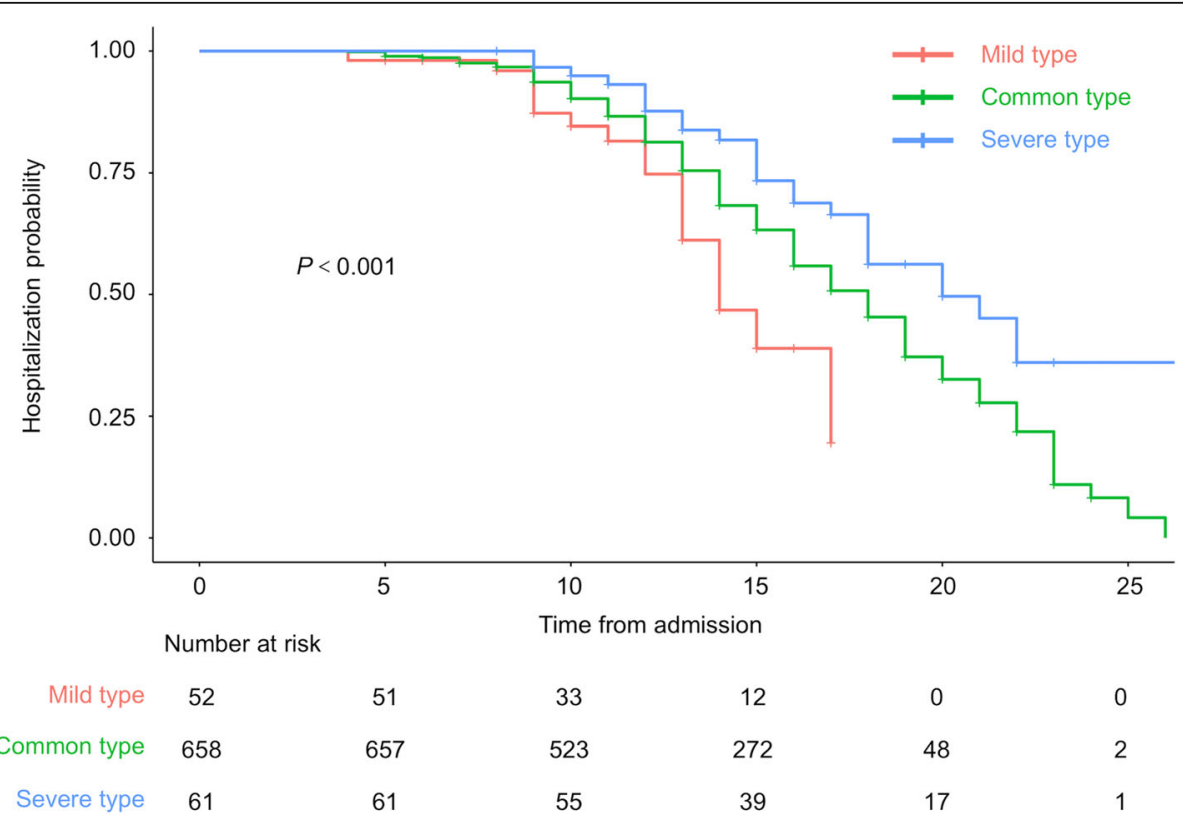

Fig. 1 Kaplan-Meier analysis showed a significant difference in hospitalization time among mild type, common type and severe type 
Table 4 Risk factors for the severity of illness in patients with COVID-19

\begin{tabular}{|c|c|c|c|c|c|c|}
\hline \multirow[t]{2}{*}{ Variables } & \multicolumn{3}{|c|}{ Univariate analysis } & \multicolumn{3}{|c|}{ Multivariate analysis } \\
\hline & $O R$ & $95 \% \mathrm{Cl}$ & $P$ value & $O R$ & $95 \% \mathrm{Cl}$ & $P$ value \\
\hline \multicolumn{7}{|l|}{ Age (years) } \\
\hline$\geq 66$ & 111.8 & $38.7-323.2$ & $<0.001$ & 56.5 & $17.1-186.5$ & $<0.001$ \\
\hline $41-65$ & 29.0 & $11.2-74.9$ & $<0.001$ & 14.8 & $5.2-42.1$ & $<0.001$ \\
\hline $19-40$ & 16.4 & $6.3-42.3$ & $<0.001$ & 12.7 & $4.5-35.9$ & $<0.001$ \\
\hline$\leq 18$ & 1.0 & & & 1.0 & & \\
\hline Sex (male) & 1.6 & $1.1-2.3$ & 0.024 & 1.7 & $1.2-2.6$ & 0.008 \\
\hline Current smoker & 1.5 & $0.7-3.1$ & 0.255 & & & \\
\hline Family cluster & 0.5 & $0.3-0.8$ & 0.007 & 0.9 & $0.5-1.4$ & 0.579 \\
\hline Exposure History in Wuhan & 1.1 & $0.8-1.6$ & 0.608 & & & \\
\hline Time from illness onset to first hospital admission & 1.1 & $1.0-1.2$ & $<0.001$ & 1.1 & $1.0-1.1$ & 0.071 \\
\hline \multicolumn{7}{|l|}{ Symptoms } \\
\hline Fever & 4.3 & $2.6-7.1$ & $<0.001$ & 3.6 & $2.1-6.3$ & $<0.001$ \\
\hline Cough & 2.7 & $1.8-4.1$ & $<0.001$ & 1.7 & $1.0-3.0$ & 0.041 \\
\hline Sputum production & 2.2 & $1.5-3.4$ & $<0.001$ & 1.3 & $1.0-2.1$ & 0.366 \\
\hline Hemoptysis & 7.7 & $2.8-21.3$ & $<0.001$ & 3.4 & $1.1-10.3$ & 0.032 \\
\hline Sore throat & 0.8 & $0.4-1.3$ & 0.345 & & & \\
\hline Nasal obstruction & 0.3 & $0.2-0.7$ & 0.005 & 0.6 & $0.2-1.4$ & 0.223 \\
\hline Myalgia & 2.6 & $1.5-4.5$ & 0.001 & 1.8 & $1.0-3.4$ & 0.063 \\
\hline Fatigue & 1.8 & $1.1-2.8$ & 0.022 & 1.3 & $0.7-2.2$ & 0.371 \\
\hline gastrointestinal symptoms & 2.1 & $1.2-3.6$ & 0.012 & 1.9 & $1.0-3.5$ & 0.047 \\
\hline Headache & 2.0 & $1.1-3.6$ & 0.030 & 2.0 & $1.0-4.0$ & 0.052 \\
\hline \multicolumn{7}{|l|}{ Coexisting disorder } \\
\hline Any & 3.8 & $2.5-5.9$ & $<0.001$ & 1.2 & $0.6-2.4$ & 0.660 \\
\hline Hypertension & 4.9 & $3.0-7.8$ & $<0.001$ & 2.6 & $1.2-5.6$ & 0.013 \\
\hline Heart disease & 2.5 & $0.6-10.1$ & 0.189 & & & \\
\hline Diabetes & 2.4 & $1.2-4.6$ & 0.009 & 0.8 & $0.4-1.9$ & 0.675 \\
\hline Chronic obstructive pulmonary disease & 42.0 & $4.9-363.9$ & 0.001 & 7.7 & $0.8-75.6$ & 0.081 \\
\hline Cancer & 7.3 & $1.5-35.2$ & 0.013 & 3.7 & $0.6-22.2$ & 0.149 \\
\hline Chronic liver disease & 1.6 & $0.6-3.9$ & 0.335 & & & \\
\hline Chronic renal disease & 4.3 & $0.9-20.6$ & 0.065 & & & \\
\hline
\end{tabular}

OR Odds ratio, $\mathrm{Cl}$ Confidence interval

$P<0.001], 41-65$ years $[O R=14.8,95 \% C I: 5.2-42.1$, $P<0.001], \geq 66$ years $[O R=56.5,95 \% C I: 17.1-186.5$, $P<0.001])$.

\section{Discussion}

The outbreak of COVID-19 is now becoming an enormous threat to public health. With further research of the structure and infection mechanism of respiratory, scientists found angiotensin converting enzyme 2 (ACE2) might be the site of SARS-CoV-2 binding on the surface of cells, with the same route of infection of SARS-CoV [14]. It has been proved that ACE2 might play an important role in virus transmission and infection. SARS-CoV-2 not only attacked the lung but also caused damages to many other organs, including heart, kidney, liver and central nervous system [3, 6, 15, 16]. The diagnosis of COVID-19 was complicated by the diversity in symptoms, imaging findings and the severity of illness, therefore, describing features of each subtype and exploring risk factors for the severity of illness could help clinicians to better tackle with this disease.

In this respective study, the median age of critical types was higher than the other three types, with the reason of low immunity and degeneration of related physiological function in older. The length of the incubation period is related to many factors, such as the number of pathogens, the time required for toxin production and transmission, and human immunity. The 
incubation period was shorter in severe type, probably due to poor immunity and higher viral load [17]. Fever and cough were the dominant symptoms in all subtypes, while hemoptysis was rare. Fever is a protective mechanism by activating the immune systems to resist pathogens, and cough is a reflective defense against invaders. When an individual was infected, the above two symptoms generally appeared at early stage. Although hemoptysis was an atypical symptom, it was reported that there was COVID-19 patient admitted only with hemoptysis as the initial symptom [18]. Moreover, we should be alert to the patients who didn't have a fever, due to $6.6 \%$ of severe type without fever in our study. Hypertension and diabetes were the most pervasive underlying diseases in all subtypes, and the proportion of them were higher in critical type. In consideration of the aged constituting the majority of the critical type, it is common that the rates of comorbidities increased.

According to the laboratory results, the decrease of lymphocyte occurred in $70.6 \%$ of critical type. The decrease of lymphocyte was a prominent feature of critical type in our cohort which was consistent with a previous study [19]. SARS-CoV-2 might mainly act on lymphocyte, especially $\mathrm{T}$ lymphocytes, as did SARS-CoV [6]. In addition, the increased AST and LDH implied a potential of liver and heart damage which was more common in severe and critical types.

Currently, there is no effective antiviral treatment for COVID-19 [20]. In the light of the previous clinical experience, interferon- $\alpha$, lopinavir/ritonavir and arbidol were applied for antiviral therapy in our hospital, however, the therapeutic regimen was not researched a consensus among hospitals. A retrospective study identified that proper use of corticosteroid in critical type with SARS could lead to a lower mortality and shorter hospitalization stay [21]. In our study, the dosage of glucocorticoids was limited to $40-80 \mathrm{mg} / \mathrm{d}$ to avoid side effects. Until 12 February 2020, 21 cases (40.4\%) of mild type, 273 cases (41.5\%) of common type, 27 cases (44.3\%) of severe type, and 1 case (5.9\%) of critical type discharged from hospital.

Compared with initial patients infected with SARSCoV-2 in Wuhan, the illness condition of patients in Zhejiang Province are relatively milder. None of the patients died at the end of our follow-up. This feature is obviously different from researches in Wuhan which reported a higher mortality $[10,19]$. At early stage of outbreak of COVID-19 in Wuhan, shortage of local medical resources, insufficient understanding of this disease and no effective drugs might contribute to this phenomenon.

Several risk factors for the severity of illness in patients with COVID-19 were identified in our study including male, fever, cough, hemoptysis, gastrointestinal symptoms, hypertension, and higher age-grading. Several studies demonstrated that differences in COVID-19 disease prevalence and severity were associated with sex, which was similar to our results $[3,6,19]$. One study, using single-cell sequencing, found that expression of ACE2 was more predominant in Asian men [22]. During the evolution, females develop enhanced innate and adaptive immune responses than males and are less susceptible to viral infections [23]. These above two points might be the reasons for the higher prevalence and severity of COVID-19 in men than in women. Additionally, in our study, the presence of any one of the comorbidities was higher in male compared with female (30.7\% vs $24.4 \%, P=0.048)$. We thought this result might also partly explain why men are more prone to severity illness.

Our study found increasing odds of the severity of illness was associated with gastrointestinal symptoms. A bioinformatics analysis on single-cell transcriptomes demonstrated that ACE2 was not only highly expressed in the lung AT2 cells, esophagus upper and stratified epithelial cells but also in absorptive enterocytes from ileum and colon. Recently, two independent laboratories from China declared that they have successfully isolated live SARS-CoV-2 from the stool of patients [24]. An increasing number of studies remind us that digestive system might serve as an alternative route of infection for SARS-CoV-2 [25]. We consider the digestive tract transmission of SARS-CoV-2 might impair the function of intestinal mucosal barriers and increase the production of inflammatory factors, further aggravating the severity of illness.

In addition, COVID-19 patients combined with hypertension were at higher risk for the illness severity in our study. Renin-angiotensin system (RAS) plays an important role in the pathogenesis of hypertension. It could be simply summarized as two axes, one is ACE-Ang II-AT1 axis responsible for constriction of blood vessels, and the other is ACE2-Ang-(1-7)-Mas axis with the opposite effect [26, 27]. Generally, the two axes could interact with each other and maintain the blood pressure balance. However, the balance would be broken in hypertension, with the result of a lower expression of ACE2. Once infected by SARS-CoV-2, the level of ACE2 would be even lower, followed by intensified Ang II activity. Ang II would further promote vasoconstriction, increase vascular permeability and mediate inflammatory responses, leading to illness aggravation.

There are several limitations in our study. Firstly, the retrospective design of our study might affect integrality of data and diminish its credibility, and more prospective cohort studies should be on the agenda in the future. Secondly, patients enrolled in our study only come from Zhejiang Province, and large-scale researches at the national level were urgently needed which could provide 
more reliable and comprehensive data. Thirdly, changes of the illness in different subtypes needed to be further investigated. A model for predicting the changes of disease was necessary for clinicians to better guide treatments. Moreover, laboratory results were not included in ordinal logistic regression model to explore risk factors for the severity of illness, due to the normal range of some indicators varied from different hospitals.

\section{Conclusions}

In summary, our study reported the largest cases of patients with COVID-19 in Zhejiang Province, and indicated risk factors of illness severity which was of great significance for early identification and prompt treatment. Based on the research findings, we recommend that clinicians should pay close attention to these features in patients with COVID-19 including older age, male, fever, cough, hemoptysis, gastrointestinal symptoms and hypertension, and strengthen self-protection during the outbreak of COVID-19.

\begin{abstract}
Abbreviations
WHO: World Health Organization; SARS-CoV-2: Severe acute respiratory syndrome coronavirus 2; SARS-CoV: Severe acute respiratory syndrome coronavirus; MERS-CoV: Middle East respiratory syndrome coronavirus; COVID-19: Coronavirus disease 2019; RT-PCR: Real-time reverse transcriptase polymerase chain reaction; China CDC: Chinese Center for Disease Control and Prevention; ALB: Albumin; AST: Aspartate aminotransferase; BUN: Blood urea nitrogen; CR: Creatinine; CK: Creatinine kinase; LDH: Lactate dehydrogenase; CRP: C-reactive protein; PCT: Procalcitonin; ALT: Alanine aminotransferase; TB: Total bilirubin; INR: International normalized ration; ECMO: Extracorporeal membrane oxygenation; CRRT: Continuous renalreplacement therapy; RAS: Renin-angiotensin system; ACE2: Angiotensin converting enzyme 2; ACE: Angiotensin converting enzyme; Ang II: Angiotensin II; AT1: Angiotensin type 1; Ang-(1-7): Angiotensin-(1-7)
\end{abstract}

\section{Acknowledgments}

We would like to acknowledge Health Commission of Zhejiang Province, China for coordinating data collection.

\section{Authors' contributions}

Yi-Da Yang, Lan-Juan Li and Ji-Fang Sheng designed the study, Shan-Yan Zhang coordinated the work and took the lead in drafting the manuscript and interpreting, Jiang-Shan Lian, Jian-Hua Hu and Xiao-Li Zhang developed the statistical methods, Ying-Feng Lu, Huan Cai, Jue-Qing Gu, Chan-Yuan Ye, Ci-Liang Jin, Guo-Dong Yu, Hong-Yu Jia and Yi-Min Zhang were participated in the collection of experimental data. All authors read and approved the final manuscript for publication.

\section{Funding}

This work was supported by National Major Science and Technology Research Projects for the Control and Prevention of Major Infectious Diseases in China (2017ZX10202202).

\section{Availability of data and materials}

All datasets are presented in the main paper.

\section{Ethics approval and consent to participate}

This study was approved by the Clinical Research Ethics Committee of the First Affiliated Hospital, College of Medicine, Zhejiang University (NO. IIT20200005C)

\section{Consent for publication}

Not applicable.

\section{Competing interests}

The authors declare that they have no competing interests.

Received: 30 March 2020 Accepted: 29 June 2020

Published online: 08 July 2020

\section{References}

1. Zhu N, Zhang D, Wang W, Li X, Yang B, Song J, et al. A novel coronavirus from patients with pneumonia in China, 2019. N Engl J Med. 2020;382(8): 727-33

2. Lu R, Zhao X, Li J, Niu P, Yang B, Wu H, et al. Genomic characterisation and epidemiology of 2019 novel coronavirus: implications for virus origins and receptor binding. Lancet. 2020;395(10224):565-74.

3. Guan WJ, Ni ZY, Hu Y, Liang WH, Ou CQ, He JX, et al. Clinical characteristics of coronavirus disease 2019 in China. N Engl J Med. 2020; https://doi.org/10. 1056/NEJMoa2002032.

4. WHO. Coronavirus (COVID-19) https://covid19.who.int/. Accessed 19 Apr 2020

5. Huang C, Wang Y, Li X, Ren L, Zhao J, Hu Y, et al. Clinical features of patients infected with 2019 novel coronavirus in Wuhan, China. Lancet. 2020;395(10223):497-506.

6. Chen N, Zhou M, Dong X, Qu J, Gong F, Han Y, et al. Epidemiological and clinical characteristics of 99 cases of 2019 novel coronavirus pneumonia in Wuhan, China: a descriptive study. Lancet. 2020;395(10223):507-13.

7. Wang D, Hu B, Hu C, Zhu F, Liu X, Zhang J, et al. Clinical characteristics of 138 hospitalized patients with 2019 novel coronavirus-infected pneumonia in Wuhan, China. JAMA. 2020;323(11):1061-9.

8. Chang LM, Wei L, Xie L, Zhu G, Dela Cruz CS, et al. Epidemiologic and clinical characteristics of novel coronavirus infections involving 13 patients outside Wuhan, China. JAMA. 2020;323(11):1092-3.

9. $\mathrm{Xu} X W, W u X X$, Jiang $X G, X u K J$, Ying $L J, M a C L$, et al. Clinical findings in a group of patients infected with the 2019 novel coronavirus (SARS-Cov-2) outside of Wuhan, China: retrospective case series. BMJ. 2020;368:m606.

10. Zhou F, Yu T, Du R, Fan G, Liu Y, Liu Z, et al. Clinical course and risk factors for mortality of adult inpatients with COVID-19 in Wuhan, China: a retrospective cohort study. Lancet. 2020;395(10229):1054-62.

11. Wu Z, McGoogan JM. Characteristics of and important lessons from the coronavirus disease 2019 (covid-19) outbreak in China: summary of a report of 72314 cases from the Chinese Center for Disease Control and Prevention. JAMA. 2020;323(13):1239-42.

12. WHO. Clinical management of severe acute respiratory infection when novel coronavirus (nCoV) infection is suspected https://www.who.int/ publications-detail/clinical-management-of-severe-acute-respiratoryinfection-when-novel-coronavirus-(ncov)-infection-is-suspected. Accessed 13 Mar 2020.

13. China NHCotPsRo. Chinese management guideline for COVID-19(version 6 . 0) http://www.nhc.gov.cn/yzygj/s7653p/202002/8334a8326dd94d329df351 d7da8aefc2.shtml. Accessed 19 Feb 2020.

14. Zhang H, Penninger JM, Li Y, Zhong N, Slutsky AS. Angiotensin-converting enzyme 2 (ACE2) as a SARS-CoV-2 receptor: molecular mechanisms and potential therapeutic target. Intensive Care Med. 2020;46(4):586-90.

15. Bangash MN, Patel J, Parekh D. COVID-19 and the liver: little cause for concern. Lancet Gastroenterol Hepatol. 2020;5(6):529-30.

16. Mao L, Jin H, Wang M, Hu Y, Chen S, He Q, et al. Neurologic manifestations of hospitalized patients with coronavirus disease 2019 in Wuhan, China. JAMA Neurol. 2020;77(6):1-9.

17. Zheng S, Fan J, Yu F, Feng B, Lou B, Zou Q, et al. Viral load dynamics and disease severity in patients infected with SARS-CoV-2 in Zhejiang province, China, January-march 2020: retrospective cohort study. BMJ. 2020;369: m1443.

18. Shi F, Yu Q, Huang W, Tan C. 2019 novel coronavirus (COVID-19) pneumonia with hemoptysis as the initial symptom: CT and clinical features. Korean J Radiol. 2020;21(5):537-40.

19. Yang $X, Y u$ Y, Xu J, Shu H, Xia J, Liu H, et al. Clinical course and outcomes of critically ill patients with SARS-CoV-2 pneumonia in Wuhan, China: a singlecentered, retrospective, observational study. Lancet Respir Med. 2020;8(5): 475-81.

20. Cao B, Wang Y, Wen D, Liu W, Wang J, Fan G, et al. A trial of lopinavirritonavir in adults hospitalized with severe COVID-19. N Engl J Med. 2020; 382(19):1787-99. 
21. Chen RC, Tang XP, Tan SY, Liang BL, Wan ZY, Fang JQ, et al. Treatment of severe acute respiratory syndrome with glucosteroids: the Guangzhou experience. Chest. 2006;129(6):1441-52.

22. Cai H. Sex difference and smoking predisposition in patients with COVID-19. Lancet Respir Med. 2020;8(4):e20.

23. Jaillon S, Berthenet K, Garlanda C. Sexual dimorphism in innate immunity. Clin Rev Allergy Immunol. 2019;56(3):308-21.

24. Gu J, Han B, Wang J. COVID-19: gastrointestinal manifestations and potential fecal-oral transmission. Gastroenterology. 2020;158(6):1518-9.

25. Bonato G, Dioscoridi L, Mutignani M. Faecal-oral transmission of SARS-COV2: practical implications. Gastroenterology. 2020;S0016-5085(20):30449-2. https://doi.org/10.1053/j.gastro.2020.03.066.

26. Colafella KM, Hilliard LM, Denton KM. Epochs in the depressor/pressor balance of the renin-angiotensin system. Clin Sci (Lond). 2016;130(10):761-71.

27. Santos RAS, Sampaio WO, Alzamora AC, Motta-Santos D, Alenina N, Bader $\mathrm{M}$, et al. The ACE2/angiotensin-(1-7)/MAS axis of the renin-angiotensin system: focus on angiotensin-(1-7). Physiol Rev. 2018:98(1):505-53.

Ready to submit your research? Choose BMC and benefit from:

- fast, convenient online submission

- thorough peer review by experienced researchers in your field

- rapid publication on acceptance

- support for research data, including large and complex data types

- gold Open Access which fosters wider collaboration and increased citations

- maximum visibility for your research: over $100 \mathrm{M}$ website views per year

At BMC, research is always in progress.

Learn more biomedcentral.com/submissions 